siblen Inhibitoren wie beispielsweise Aspirin bindet Ticagrelor reversibel an den ADP-Rezeptor, das Medikament liegt in hohen Konzentrationen im Plasma vor.

In einem Letter to the Editor beschreiben Julia J. M. Eekels von der Universitätsmedizin in Greifswald und Kollegen anhand eines Fallberichts, dass freie P2Y12-Inhibitoren im Patientenplasma Funktionstests für heparininduzierte Thrombozytopenie (HIT) beeinträchtigen können. HIT kann eine schwerwiegende Nebenwirkung der Heparintherapie sein, bei der thrombogene Antikörper gegen Heparin-Plättchenfaktor-4-Komplexe (PF4) gebildet werden, was zu einem erhöhten Thromboserisiko führt. Klinisch relevant ist jedoch nur ein Teil der Anti-PF4/Heparin-Antikörper, die Thrombozyten aktivieren. Bei einigen Patientenpopulationen, z. B. solchen, die sich einer Herzoperation unterziehen, macht dies $<25 \%$ der durch Antigentests nachgewiesenen Anti-PF4/Heparin-Antikörper aus. Klinisch relevante Anti-PF4/HeparinAntikörper aktivieren typischerweise gewaschene Thrombozyten gesunder Spender in Gegenwart von Patientenserum und Heparin im HIPA-Test (heparininduzierte Thrombozytenaktivierung) oder im Serotoninfreisetzungstest. Die Thrombozytenaktivierung durch HIT-Antikörper wird über einen Thrombozytenrezeptor vermittelt und hängt von der Co-Signaltransduktion über den P2Y12-ADP-Rezeptor ab, der durch Ticagrelor blockiert wird.

\section{Ticagrelor: falsch negative Funktionstests bei heparininduzierter Thrombozytopenie}

Eekels JJM et al. Ticagrelor causes false-negative functional tests for heparin-induced thrombocytopenia. Blood 2020; 135: 875-878

Ticagrelor ist ein Inhibitor des ADP-Rezeptors P2Y12, der als Mittel der Wahl zur Vorbeugung von atherothrombotischen Ereignissen bei Patienten mit einem akuten Koronarsyndrom eingesetzt wird. Im Gegensatz zu irrever-
Ticagrelor zugegeben (Endkonzentrationen: 15,6, 31,3, 62,5, 125, 250, 500 und $1000 \mathrm{ng} / \mathrm{ml}$; In-vivo-Bereich: 227$770 \mathrm{ng} / \mathrm{ml}$ ). Serum des Indexpatienten und bekannte HIPA ${ }^{+}$-Seren mit TicagrelorZusatz wurden mit dem Ticagrelor-Antidot PB2452 inkubiert. Mit Ticagrelor angereicherte $\mathrm{HIPA}^{+}$-Seren wurden mit $20 \mathrm{mg}$ Aktivkohletabletten inkubiert.

Mit Ausnahme von einem getesteten Serum hemmte Ticagrelor in allen getesteten Seren dosisabhängig den HIPA-Test, wenn die Konzentrationen im Serum diejenigen im klinischen Steady State (227770 ng/ml) erreichten. Im Gegensatz zum Ticagrelor-haltigen Serum aktivierte die gereinigte lgG-Fraktion die Thrombozyten im HIPA-Test deutlich; die erneute Zugabe von Ticagrelor hemmte den HIPA-Test erneut. Auch in Gegenwart des TicagrelorAntidots wurden das Serum des Indexpatienten und die Ticagrelor-haltigen Patientenseren im HIPA-Test positiv getestet. Als Eekels und ihr Team schließlich 3 zuvor bestätigte $\mathrm{HIPA}^{+}$-Seren, denen Ticagrelor zugegeben war, mit Aktivkohle inkubierten, wurden die gereinigten Seren im HIPA-Test erneut positiv getestet.

\section{FAZIT}

Die Daten zeigen, dass Ticagrelor, das während der Behandlung mit Ticagrelor im Patientenserum vorhanden ist, den funktionellen Assay für HIT hemmt. Die Hemmung kann gemindert werden durch Isolierung der IgG-Fraktion aus dem Patientenserum, Vorinkubation des Serums mit dem Ticagrelor-Antidot PB2452 oder mit Aktivkohlepulver. Dies ist von besonderer Bedeutung für die Testung von Herzpatienten mit einer HIT-Vorgeschichte, bei denen eine erneute Heparinexposition während der kardiopulmonalen Bypassoperation geplant ist.

Dr. Michaela Bitzer, Tübingen 